\title{
Pengaruh Fungsi Kepemimpinan Kompensasi dan Kepuasan Kerja Terhadap Kinerja Pegawai Dinas Lingkungan Hidup Kota Cimahi
}

\author{
Setya Indrawanto \\ STAI Sabili Bandung, Jawa Barat, Indonesia \\ Email : setyaindrawanto77@gmail.com
}

(Diterima: Feb 2021; Direvisi: Maret 2021; Dipublikasikan: Mei 2021)

\begin{abstract}
ABSTRAK
Penelitian Ini Berjudul "Pengaruh Fungsi Kepemimpinan Kompensasi Dan Kepuasan Kerja Terhadap Kinerja Pegawai Dinas Lingkungan Hidup Kota Cimahi. Tujuan Penelitian Ini Untuk Menganalisis Pengaruh Fungsi kepemimpinan, kopensasi terhadap Kepuasan Kerja, Pengaruh Fungsi Kepemimpinan Konpensasi Dan Kepuasam Terhadap Pegawai. Penelitian Menggunakan Analisis Jalur, \{Path Analisis|\}. Populasi Penelitian Ini Adalah 50 ASN Kota Cimahi Tahun 2018 Dengan Jumlah Sample Sebanyak 50 Orang Yang Dengan System Probalitiy Sampel, Setiap Populasi Bisa Dijadikan Sampel. Hasil Penelitian Menunjukkan Fungsi Kepemimpinan, Kompensasi Dan Kepuasan Kerja Mempengaruhi Kinerja Pegawai Secara Positif Dan Signifikan Dengan Nilai T Hitung Masing-Masing Untuk Fungsi Kepemimpinan $=0.577$, Kompensasi $=0.303$, Dan Kepuasan= 0,293 Dimana Nilai T Hitung > T Tabel Dan Nilai Nilai Signifikansi Kurang Dari 0,05. Nilai R2 Sebesar 0,807 Artinya Nilai Koefisien Determinasi = 80,7 \%.Maknanya Fungsi Kepemimpinan, Kompensasi, Kepuasan Memberikan Kontribusi Untuk Mempengaruhi Kinerja Pegawai Sebesar 80,7 \%.Persamaan Analisis Jalur Y= Pyx1x1 + Pyx2x2 + Pyx3x3 + E.Y=0,577 X1 + 0,303 X2 + 0, 293 X3 + 0,193 E. Berdasarkan hasil temuan ini maka perlu dilakukan upaya-upaya untuk meningkatkan kinerja pegawai yang dapat dilakukan dengan melakukan usaha yang terarah dan terpadu serta dilaksanakan dengan konsisten dan berkesinambungan agar dapat mencapai kepuasan kerja sehingga dapat mempengaruhi kinerja karyawan.
\end{abstract}

Kata Kunci: Fungsi Kepemimpinan, Kompensasi, Kepuasan, Kinerja 


\section{PENDAHULUAN}

SDM adalah modal dasar pembangunan yang terdiri atas dimensi kuntitatif yaitu jumlah dan struktur penduduk, serta dimensi kualitatif yaitu mutu hidup penduduk. Disamping itu, SDM juga merupakan faktor dominan yang harus diperhatikan dalam penyelenggaraan pembangunan guna memperlancar pencapaian sasaran pembangunan nasional yaitu antara lain kualitas manusia dan masyarakat Indonesia dan penguasaannya terhadap IPTEK, serta disiplin nasional yang merupakan perwujudan kepatuhan dan kepada hukum dan norma-norma yang berlaku dalam masyarakat.

Sumber Daya Manusia (SDM) mempunyai peranan utama pada suatu instansi tidak karena tupoksinya semata dalam rangka mewujudkan tujuan organisasi tetapi juga lingkungan kerja yang kurang nyaman situasi kerja yang kurang kondusif rendahnya interaksi antar pegawai dapat memberikan pengaruh menurunnya semangat serta kurangnya keinginan untuk bekerja dengan baik hingga berakibat minimnya kemampuan, dan rendahnya kualitas serta kuantitas pekerjaan yang dihasilkan. Kebutuhan pegawai serta kepuasan kerja hendaknya menjadi perhatian pimpinan terhadap ke tiga faktor tersebut agar kinerja pegawai tetap maksimal. Setiap pimpinan menginginkan hasil kerja yang optimal dari pegawainya maka untuk mewujudkannya dibutuhkan pegawai yang memiliki kemampuan kerja yang berkualitas dan kuantitas tinggi.

Kinerja pegawai merupakan hasil kerja yang dicapai seseorang dalam melaksanakan tugas-tugas yang dibebankan kepadanya. Kinerja pegawai meliputi kualitas dan kuantitas yang dihasilkan serta keandalan dalam bekerja. Karyawan dapat bekerja dengan baik bila memiliki kinerja yang tinggi sehingga dapat menghasilkan kerja yang baik pula. Dengan adanya kinerja tinggi yang dimiliki pegawai, diharapkan tujuan organisasi dapat tercapai. Kenyataan dilapangan dalam hal ini organisasi masih banyak ditemukan pegawainya yang kurang semangat, disiplin yang rendah, cenderung apatis yang berdampak pada menurunnya kinerja.

Kesempurnaan aparatur Negara dibutuhkan Pegawai Negeri yang professional sebagai salah satu penentu tercapainya tujuan pembangunan nasional disamping faktor-faktor penentu lainnya, Mengingat Pegawai Negeri sebagai pelaksana Pemerintah dan penyelenggara pemerintahan maka diperlukan Pegawai Negeri yang professional dalam hal ini perlu adanya pembinaan terhadap Pegawai Negeri dengan sebaik-baiknya sehingga dapat memacu semangat dan keinginan pegawai untuk bekerja secara optimal guna tercapainya tujuan pembangunan nasional pada umumnya dan tujuan instansi dimana pegawai tersebut bekerja dalam memberikan pelayanan kepada masyarakat khususnya.

Pengaruh pemimpin dalam menyelenggarakan tugas-tugas kepemimpinannya sangat penting, sejauh mana seorang pemimpin memberikan penekanan sebagai pemrakarsa struktur tugas yang harus dilaksanakan bawahannya dalam mencapai berbagai tujuan organisasi baik yang bersifat tujuan ekonomi, 
sosial atau politik sebagian besar tergantung kepada kemampuan para pemimpin dalam unit organisasi yang bersangkutan. Faktor lain yang juga berpengaruh terhadap kinerja adalah faktor kompensasi.

Tujuan dari Penilaian tersebut diatas dimaksudkan untuk memperoleh bahan-bahan pertimbangan yang obyektif berdasarkan sistem karir dan sistem prestasi kerja dalam rangka pembinaan Aparatur Sipil Negaral. Penilaian Sasaran Kerja Pegawai ini diberikan pada ASN oleh pejabat yang berwenang dalam lingkungannya Aparatur Sipil Negaral tersebut.

\section{METODE PENELITIAN}

Metode penelitian bertujuan untuk mendapatkan data yang lengkap, mendalam, dan kredibel. Metode penelitian merupakan rangkaian cara atau pelaksanaan penelitian yang didasari oleh asumsiasumsi dasar. Ada empat kata kunci yang terkandung didalamnya, yaitu cara ilmiah, data, tujuan, dan kegunaan. Cara ilmiah berarti kegiatan penelitian itu berdasarkan pada ciriciri keilmuan, yaitu rasional, empiris, dan sistematis. Rasional yaitu kegiatan penelitian ini dilakukan dengan caracara yang masuk akal, sehingga terjangkau oleh pikiran manusia. Empiris yaitu cara-cara yang dilakukan itu dapat diamati oleh indra manusia, sehingga orang lain dapat mengamati dan mengetahui cara-cara yang digunakan. Sistematis yaitu proses yang digunakan dalam penelitian menggunakan langkahlangkah tertentu yang bersifat logis.

Dilihat dari sifatnya penelitian ini termasuk penelitian deskriptif dan verifikatif dengan jenis metode survei.
Menurut Moh. Nazir (2003:54-56), metode penelitian deskriptif dengan jenis metode survei yaitu meneliti suatu objek dengan mendeskripsikan secara sistematis, aktual, dan akurat mengenai fakta-fakta atas fenomena yang ada dan diteliti serta menerangkan hubungan, menguji hipotesis, membuat prediksi, dan mendapatkan makna serta implikasinya. Melalui jenis penelitian deskriptif maka dapat diperoleh deskripsi mengenai variabel dan sub variabel fungsi kepemimpinan, kompensasi, kepuasan kerja terhadap kinerja pegawai.

Sedangkan yang dimaksud dengan penelitian verifikatif menurut Suharsimi (2013:7) adalah penelitian yang pada dasarnya menguji kebenaran melalui pengumpulan data di lapangan. Sehubungan dengan jenis penelitian yang digunakan, maka desain penelitian ini adalah eksplanatori non-eksperimental, dengan menggunakan metode survey. Menurut Sekaran (2011), adapun ciriciri dari metode survey adalah tujuannya dapat bersifat deskriptif dan juga verifikatif, eksplanatori atau konfirmatori, data dikumpulkan dari sampel yang telah ditentukan, data variabel penelitian dijaring dengan menggunakan alat mengumpulan data tertentu yaitu kuesioner.

Analisis jalur digunakan untuk menunjukkan hubungan yang memperlihatkan seberapa besar pengaruh sebuah variabel tertentu baik pengaruh langsung maupun tidak langsung terhadap variabel lainnya dalam hal ini persoalannya adalah sebab akibat. Dalam analisis jalur ini akan digunakan istilah yaitu variabel eksogen yang merupakan variabel 
penyebab (X). Variabel endogen yang

Bentuk umum persamaan jalur :

merupakan akibat $(\mathrm{Y})$

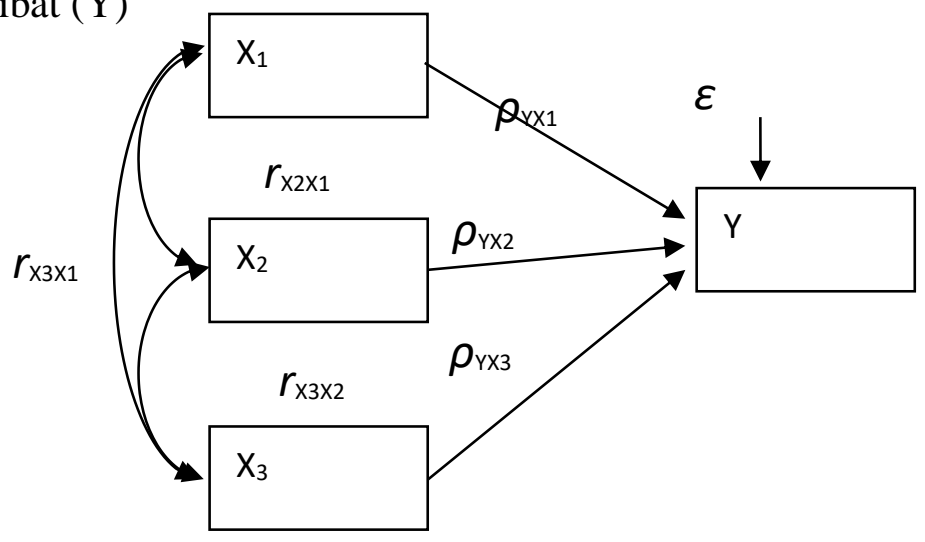

Gambar 1. Diagram antar variabel yang mencerminkan hubungan antar vaiabel dan pengaruh $\mathrm{X}$ terhadap $\mathrm{Y}$

\section{PEMBAHASAN}

Analisis Jalur digunakan untuk mengetahui apakah data mendukung teori, yang secara a-priori dihipotesiskan, yang mencakup kaitan structural antar variabel terukur.
Analisis Jalur atau yang lebih dikenal luas sebagai Path Analysis merupakan suatu metode pendekomposisian korelasi kedalam bagian-bagian yang berbeda untuk menginterpretasikan suatu pengaruh (effect).

Tabel 1. Hasil Uji Reliabilitas

\begin{tabular}{|c|l|c|c|c|}
\hline No. & \multicolumn{1}{|c|}{ Variabel } & Skor & R Kritis & Kategori \\
\hline 1. & Kepemimpinan $\left(\mathrm{X}_{1}\right)$ & 0,772 & 0,700 & Reliabel \\
\hline 2. & Kompensasi $\left(\mathrm{X}_{2}\right)$ & 0,711 & 0,700 & Reliabel \\
\hline 3. & Kepuasan Kerja $\left(\mathrm{X}_{3}\right)$ & 0,817 & 0,700 & Reliabel \\
\hline 4. & Kinerja Aparatur $(\mathrm{Y})$ & 0,936 & 0,700 & Reliabel \\
\hline
\end{tabular}

Sumber: Data Primer diolah kembali

Hasil uji reliabilitas di atas dapat dinyatakan bahwa semua variabel termasuk kategori reliabel, karena skornya $>0,70$. Dengan demikian instrumen penelitian yang digunakan masing-masing variabel pada penelitian ini dapat dinyatakan reliabel dan benar-benar sebagai alat ukur yang handal dan memiliki tingkat kestabilan yang tinggi, dalam arti alat ukur tersebut apabila dilakukan secara berulang, hasil dari pengujian instrumen tersebut akan menunjukkan hasil yang tetap. 
Tabel 2. Uji Normalisasi Alat Ukur

One-Sample Kolmogorov-Smirnov Test

\begin{tabular}{|ll|r|r|r|r|}
\hline & & \multicolumn{1}{|c|}{ Fungsi X1 } & \multicolumn{1}{|c|}{ X2 } & \multicolumn{1}{|c|}{ X3 } & \multicolumn{1}{|c|}{ Y } \\
\hline N & & 50 & 50 & 50 & 50 \\
Normal & Mean & 61,7800 & 53,3400 & 50,3600 & 61,4800 \\
Parameters, ${ }^{\mathrm{a}, \mathrm{b}}$ & Std, & 10,40269 & 13,86614 & 10,67662 & 16,13874 \\
& Deviation & & & & \\
Most Extreme & Absolute &, 184 &, 304 &, 201 &, 237 \\
Differences & Positive &, 080 &, 181 &, 119 &, 168 \\
& Negative &,- 184 &,- 304 &,- 201 &,- 237 \\
& 1,305 & 1,150 & 1,124 & 1,175 \\
Kolmogorov-Smirnov Z &, 066 &, 100 &, 135 &, 097 \\
Asymp, Sig, (2-tailed)
\end{tabular}

a, Test distribution is Normal,

b, Calculated from data,

$\begin{array}{lrr}\text { Hasil Uji } & \text { normalitas } & \text { dengan } \\ \text { program } & \text { SPSS Sangat Tidak }\end{array}$ Setuju adalah sebagaimana pada Tabel uji normalitas, yang menunjukkan bahwa uji normalitas data untuk variabel penelitian yang sudah diuji sebelumnya secara manual dengan uji Kolmogorov-Smirnov. Pengujian dengan SPSangat Tidak Setuju berdasarkan pada uji Kolmogorov-Smirnov. Hipotesis yang diuji adalah :

$\mathrm{H}_{0}: p$-value $<0.05$ Sampel tidak berasal dari populasi yang berdistribusi normal

$\mathrm{H}_{1}: p$-value $>0.05$ Sampel berasal dari populasi yang berdistribusi normal

Penyampaikan hasil penelitian menjawab masalah deskriptif terhadap lima variabel yang diteliti adalah

Tabel 3 Koefisien Korelasi Antar Variabel

\begin{tabular}{|ll|r|r|r|}
\hline & \multicolumn{1}{|c|}{$\begin{array}{c}\text { Fungsi } \\
\text { Kepemimpinan }\end{array}$} & Kompensasi & Kepuasan Kerja \\
\hline Fungsi Kepemimpinan & Pearson & 1 &, $268^{*}$ &, 261 \\
& Correlation & &, 050 &, 057 \\
& Sig. (2-tailed) & 50 & 50 & 50 \\
& $\mathrm{~N}$ &, $268^{*}$ & 1 &, $645^{* *}$ \\
\hline Kompensasi & Pearson &, 050 & &, 000 \\
& Correlation & & & \\
& Sig. (2-tailed) & & & \\
\hline
\end{tabular}

dengan menampilkan hasil perhitungan dengan nilai frekuensi, persentase, dan rata-rata untuk masing-masing indikator yang mendukung variabel melalui dimensidimensi. Rincian variabel dalam dukungan masing-masing indikator adalah sebagai berikut: (1) Variabel Fungsi Kepemimpinan terdiri dari 15 pernyataan; (2) variabel Kompensasi terdiri dari 18 pernyataan; (3) variabel Kepuasan Kerja terdiri dari 15 pernyataan dan (4) variabel Kinerja terdiri dari 19 pernyataan.Dalam analisis jalur yang distandarkan korelasi dapat dipecah kedalam komponen-komponen struktural (kausal) dan nonstruktural (nonkausal) didasarkan teori yang dinyatakan dalam diagram jalur. 


\begin{tabular}{|ll|r|r|r|} 
& $\mathrm{N}$ & 50 & 50 & 50 \\
\hline Kepuasan Kerja & Pearson &, 261 &, $645^{* *}$ & 1 \\
& Correlation &, 057 &, 000 & \\
& Sig. (2-tailed) & 50 & 50 & 50 \\
& $\mathrm{~N}$ & & \\
\end{tabular}

*. Correlation is significant at the 0.05 level (2-tailed).

**. Correlation is significant at the 0.01 level (2-tailed).

Sumber : Data Hasil pengolahan melalui Sofware SPSS

Berdasarkan hasil perhitungan diperoleh besaran koefisien jalur dengan menggunakan program SPSS sebagai berikut

Tabel 4 Koefisien Jalur

\begin{tabular}{|c|c|c|c|c|c|c|}
\hline \multirow{2}{*}{\multicolumn{2}{|c|}{ Model }} & \multicolumn{2}{|c|}{ Unstandardized Coefficients } & \multirow{2}{*}{$\begin{array}{c}\text { Standardized } \\
\text { Coefficients } \\
\text { Beta }\end{array}$} & \multirow[b]{2}{*}{$\mathrm{t}$} & \multirow[b]{2}{*}{ Sig. } \\
\hline & & $\mathrm{B}$ & Std. Error & & & \\
\hline \multirow[t]{4}{*}{1} & (Constant) & $-10,163$ & 3,850 & & $-2,639$ & ,011 \\
\hline & $\begin{array}{l}\text { Fungsi } \\
\text { Kepemimpinan }\end{array}$ &, 510 & 057 & ,577 & 8,891 &, 000 \\
\hline & Kompensasi & ,395 & , 107 & ,303 & 3,694 & ,001 \\
\hline & Kepuasan Kerja & ,367 & 102 & 293 & 3,583 & 001 \\
\hline
\end{tabular}

a. Dependent Variable: Kinerja Pegawai

Hasil analisis jalur [Path Kepuasan Kerja terhadap Kinerja Analisis] variabel Fungsi Pegawai dapat dijelas pada gambar di Kepemimpinan , Kompensasi dan bawah ini:

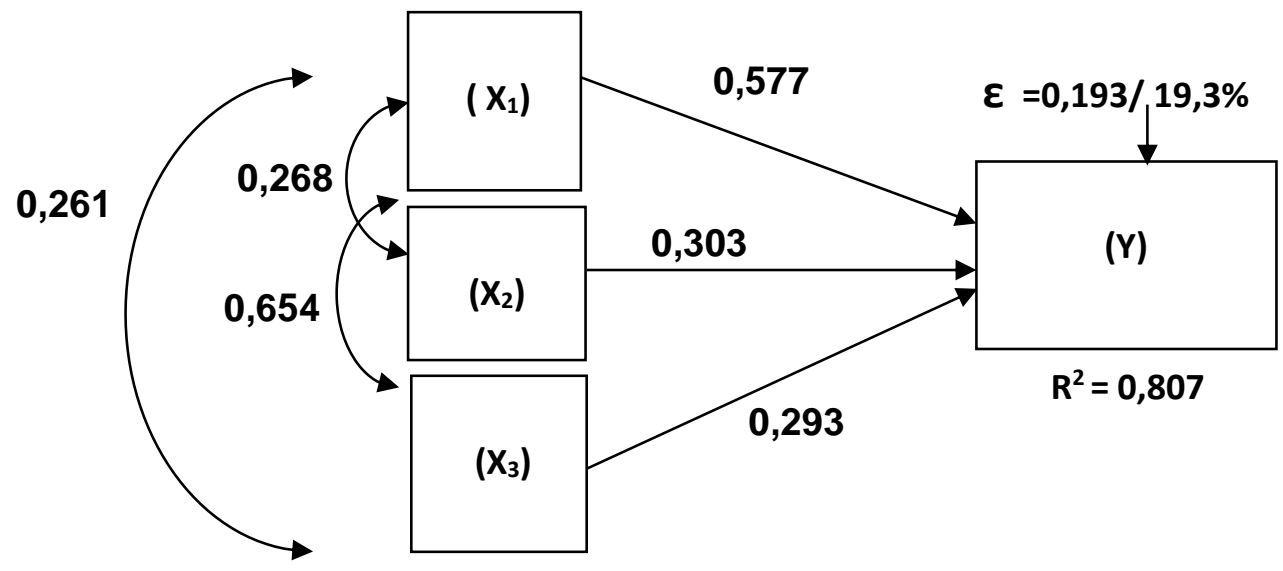

Gambar 2. Diagram Hasil analisis jalur [Path Analisis

Berdasarkan gambar tersebut di atas, maka diperoleh persamaan jalur sebagai berikut;

$$
Y=0,577 x_{1}+0,303 x_{2}+
$$
$0,293 x_{3}+\mathbf{C}$

Besarnya pengaruh dari masingmasing variabel bebas terhadap variabel terikat baik pengaruh langsung (Direct Effect) maupun pengaruh tidak langsung (Indirect Effect) dapat di lihat pada tabel berikut ini : 
Tabel 5. Perhitungan Pengaruh langsung dan pengaruh tidak langsung

Variabel bebas terhadap variabel terikat

\begin{tabular}{|c|c|c|c|c|}
\hline \multicolumn{2}{|c|}{ Variabel } & \multicolumn{3}{|c|}{ Pengaruh Langsung } \\
\hline \multicolumn{2}{|c|}{ Fungsi Kepemimpinan } & \multicolumn{3}{|c|}{$(0,577 \times 0,577) \times 100 \%=33,29 \%$} \\
\hline \multicolumn{2}{|c|}{ Kompensasi } & \multicolumn{3}{|c|}{$(0,303 \times 0,303) \times 100 \%=9,18 \%$} \\
\hline \multicolumn{2}{|l|}{ Kepuasan Kerja } & \multicolumn{3}{|c|}{$(0,293 \times 0,293) \times 100 \%=8,58 \%$} \\
\hline \multirow{2}{*}{ Variabel } & \multicolumn{4}{|c|}{ Pengaruh Tidak Langsung } \\
\hline & Fun & pemimpinan & Kompensasi & $\mathbf{x} 3$ \\
\hline $\begin{array}{l}\text { Fungsi } \\
\text { Kepemimpinan }\end{array}$ & \multicolumn{2}{|r|}{ - } & $\begin{array}{c}(0,577 \times 0,303 \times 0,268) \times 10 \\
0 \%\end{array}$ & $\begin{array}{c}(0,577 \times 0,293 \times 0,261) \times 10 \\
0 \%\end{array}$ \\
\hline Kompensasi & \multicolumn{2}{|c|}{$\begin{array}{c}(0,577 \times 0,303 \times 0,268) \times 1 \\
00 \%\end{array}$} & - & $\begin{array}{c}(0,303 \times 0,293 \times 0,645) \times 10 \\
0 \%\end{array}$ \\
\hline Kepuasan Kerja & \multicolumn{2}{|c|}{$\begin{array}{c}(0,577 \times 0,293 \times 0,261) \times 1 \\
00 \%\end{array}$} & $\begin{array}{c}(0,303 \times 0,293 \times 0,645) \times 10 \\
0 \%\end{array}$ & - \\
\hline
\end{tabular}

Sumber : Hasil perhitungan

Tabel 6. Rekapitulasi Pengaruh langsung dan pengaruh tidak langsung Variabel bebas terhadap variabel terikat

\begin{tabular}{|l|c|c|c|c|c|c|}
\hline \multirow{2}{*}{ Variabel } & \multirow{2}{*}{$\begin{array}{c}\text { Pengaruh } \\
\text { Langsung }\end{array}$} & \multicolumn{4}{|c|}{ Pengaruh Tidak Langsung } & \multirow{2}{*}{$\begin{array}{c}\text { Total } \\
\text { Pengaruh }\end{array}$} \\
\cline { 3 - 6 } & & $\mathbf{x} 1$ & $\mathbf{x}$ & $\mathbf{x} 3$ & Total & \\
\hline $\begin{array}{l}\text { Fungsi } \\
\text { Kepemimpinan }\end{array}$ & $33,29 \%$ & & $4,69 \%$ & $4,41 \%$ & $9,10 \%$ & $42,39 \%$ \\
\hline Kompensasi & $9,18 \%$ & $4,69 \%$ & & $5,73 \%$ & $10,41 \%$ & $19,59 \%$ \\
\hline Kepuasan Kerja & $8,58 \%$ & $4,41 \%$ & $5,73 \%$ & & $10,14 \%$ & $18,72 \%$ \\
\hline \multicolumn{7}{|c|}{ Total Pengaruh x Ke Y } \\
\hline
\end{tabular}

Sumber : Hasil perhitungan

\section{KESIMPULAN DAN SARAN}

\section{A. Kesimpulan}

1. Berdasarkan hasil pengolahan data, fungsi kepemimpinan berada pada kriteria cenderung baik. sebanyak $56,4 \%$ menunjukan jawaban baik atas fungsi pimpinan dinas.

2. Berdasarkan hasil pengolahan data, berada pada kriteria Cenderung Baik. Sebanyak
$52 \%$

responden mempersepsikan setuju atas Kompensasi di Dinas Lingkungan Hidup Kota Cimahi.

3. Berdasarkan hasil pengolahan data, dapat disimpulkan bahwa Variabel Kepuasan Kerja berada pada rentang kriteria cenderung belum baik. Sebanyak $53,6 \%$ responden 
mempersepsikan belum baik mengenai Kepuasan Kerja di Dinas Lingkungan Hidup Kota Cimahi.

4. Berdasarkan hasil pengolahan data, Kepemimpinan berpengaruh paling besar terhadap kinerja pegawai. Hal ini berarti bahwa bahwa baik buruknya atau tinggi rendahnya kinerja pegawai di Dinas Lingkungan Hidup Kota Cimahi sangat bergantung kepada fungsi kepemimpinan. Semakin baik fungsi kepemimpinan maka kinerja pegawai akan meningkat.

5. Berdasarkan hasil pengolahan data, Kompensasi (X2) memberikan kontribusi pengaruh terbesar kedua terhadap kinerja pegawai. Hal ini menunjukan bahwa Kompensasi di Dinas Lingkungan Hidup Kota Cimahi akan membentuk kinerja pegawai, semakin baik budaya yang berkembang di lingkungan internal dinas maka akan berdampak pada pola perilaku pegawai sehingga akan mengoptimalisasi peningkatan kiinerja..

6. Variabel Kepuasan Kerja $\left(\mathrm{X}_{3}\right)$ memberikan kontribusi pengaruh terlemah terhadap kinerja pegawai Hal ini berarti kinerja pegawai di Dinas Lingkungan Hidup Kota Cimahi bergantung kepada komitmen pegawai itu sendiri.

7. Hasil perhitungan Koefisien determinasi ( $\mathrm{R}$ kuadrat) yang dinyatakan dalam persentase mengambarkan besarnya kontribusi semua variabel bebas memberikan kontribusi yang cukup besar terhadap Kinerja, namun demikian masih terdapat faktor lainnya yang mempengaruhi kinerja pegawai di Dinas Lingkungan Hidup Kota Cimahi.

\section{B. Saran}

1. Dalam meningkatkan fungsi kepemimpinan perlu adanya upaya yang kongkrit dari Pimpinan Dinas Lingkungan Hidup Kota Cimahi untuk selalu memberikan perhatian pada seluruh pegawai, pimpinan diupayakan untuk selalu berbaur dan dan berpartisipasi dengan seluruh pegawai, tanpa memandang dan membeda bedakan status dan golongan pegawai itu sendiri.

2. Dalam upaya meningkatkan Kompensasi, perlu adanya upaya pengawasan dan arahan dari pimpinan kepada seluruh pegawai terhadap seluruh aspek pekerjaan, dengan demikian akan meminimalisir tingkat kesalahan yang dilakukan oleh pegawai, dan juga pengawasan atas persaingan kerja yang terjadi antar sesama pegawai di lingkungan dinas. dalam hal ini difokuskan pada pegawai baru akan tetapi tidak menutup kemungkinan, pegawai lama pun perlu diawasi dikarenakan kesalahan tidak hanya dilakukan oleh pegawai baru, terkadang pegawai lama pun selalu ada kesalahan dalam bekerja.

3. Untuk meningkatkan Kepuasan Kerja, perlu adanya 
Pengembangan SDM di Dinas Lingkungan Hidup Kota Cimahi ini merupakan bagian dari manajemen. Sebagai bagian yang memberikan pengaruh besar pada dinas, hal ini pastinya tidak bisa dianggap sepele. Itulah sebabnya, Dinas Lingkungan Hidup Kota Cimahi harus terus mempersiapkan generasi yang tangguh dan siap bereksplorasi dengan segala kemampuan yang dimiliki.

4. Dalam upaya peningkatan kinerja pegawai Dinas Lingkungan Hidup Kota Cimahi, perlu adanya penilaian kinerja pegawai . Hal tersebut sangat perlu untuk dilakukan guna sebagai bahan evaluasi kinerja pegawai , arsip tenaga kerja, penilaian kinerja itu sendiri dibandingkan standar kerja (standar operasional) yang telah ditetapkan oleh suatu perusahaan/organisasi, identifikasi letak kesalahan (error staffing), pelatihan dan pengembangan dan lain sebangainya.

5. Dalam upaya peningkatan pengaruh fungsi kepemimpinan terhadap kinerja pegawai, perlu adanya komitmen yang baik dari pimpinan untuk menciptakan dinas yang baik, apabila fungsi kepemimpinan tidak berjalan semestinya akan memberikan dampak yang buruk pada kinerja.

6. Upaya peningkatan Kompensasi dalam mempengaruhi kinerja adalah dengan cara mendorong dan meningkatkan kemampuan para pegawai dengan berbagai pelatihan.

7. Dalam upaya meningkatkan Kepuasan Kerja dalam meningkatkan kinerja dengan cara melakukan studi terhadap komitmen yang didasari pada suatu keyakinan bahwa pegawai yang berkomitmen akan menguntungkan bagi organisasi karena kemampuan potensialnya dan mengurangi turnover dan meningkatkan kinerja pegawai .

8. Dalam upaya meningkatkan kinerja pegawai yaitu dengan cara meningkatkan kapabilitas seseorang untuk menggunakan keterampilan-keterampilan yang dimiliki, guna menghasilkan kinerja layanan terbaik. Selain itu perlu adanya peningkatan pengetahuan, keterampilan dan kemampuan atau kapabilitas seluruh pegawai yang telah menjadi bagian sehingga mewarnai perilaku kognitif, efektif dan psikomotoriknya dalam bekerja sebagai pegawai Dinas Lingkungan Hidup Kota Cimahi.

\section{DAFTAR PUSTAKA}

Anatan, Lina, dan Lena Elliten. (2007). Manajemen Sumber Daya MAnusia dalam Bisnis Modern. Bandung: Alfabeta.

Baharuddin, A., \& Salam, R. (2020). Pengaruh Kepemimpinan Dan Motivasi Terhadap Kinerja Karyawan Pada PT. Niaga Bangun Persada Di Jakarta. JENIUS (Jurnal Ilmiah Manajemen Sumber Daya Manusia), 4(1), 1-11. 
Deshler, Garry, (2003). Human Reseource Management. International Edition, USA, Pearson Education Inc, Upper Saddle River.

Mudrasah Sinungan (2000), Produktivitas Apa dan Bagaimana, Jakarta :Angkasa Persada.

Mujiono, Imam. (2002). Kepemimpinan dan Keorganisasian. Yogyakarta: UII Press.

Nurjaya, N., Erlangga, H., Hong, L. Z., \& Wijayanti, K. D. (2020). The Effect of Work Stress and Work Conflict on Employees Turnover Intention In Middle Small Micro Enterprises (MSMEs) In South Tangerang Region. International Journal of Educational Administration, Management, and Leadership, 51-62.

Robbins, Stephen, (2006), Perilaku Organisasi, Prentice Hall, edisi kesepuluh

Siagan P, Sondang. (2001). Manajemen Stratejik. Jakarta: Bumi Aksara

Sukmalana, Soelaiman. (2007). Manajemen Kineja. Jakarta: PT. Intermedia Pesonalia Utama

Sutrisno, S. (2018). Pengaruh Pelatihan Pelayanan Prima Dan
Disiplin Kerja Terhadap Kinerja Karyawan Pada PT. Sumber Sarana. JENIUS (Jurnal Ilmiah Manajemen Sumber Daya Manusia), 2(1). Thoha, Miftah,

(2003). Kepemimpinan dan manajemen. Jakarta: Raja Grafindo Persada

Tobing, Paul L. (2007). Knowlegde Management.

Konsep, Arsitektur, dan Implementasi”. Yogyakarta: Graha Ilmu.

Undang Undang no 32 tahun 2004, Otonomi Daerah

Usmara, A (editor). (2003). Paradigma Baru Manajemen Sumber Daya Manusia. Cetakan keempat, Edisi ke-2, Jogjakarta: Amara Books.

Veithzal,

Rivai. (2004).Kepemimpinan dan Perilaku Organisasi (Konsultan Bisnis dan Manajemen). Jakarta: Raja Grafindo Persada

Yuniarsih, Tjutju., Suwatno. (2006). Strategi Membangun Kinerja Produktif Melalui Kepemimpinan yang berorientasi pada Manajemen Mutu. Pidato Pengukuhan Jabatam Guru Besar Tetap dalam Bidang Ilmu Pendidikan Universitas Pendidikan Indonesia. Bandung. 